\title{
VimA is part of the maturation pathway for the major gingipains of Porphyromonas gingivalis W83
}

\author{
E. Vanterpool,† F. Roy,‡ W. Zhan,‡ S. M. Sheets, L. Sangberg \\ and H. M. Fletcher
}

Correspondence

H. M. Fletcher

hfletcher@llu.edu

Received 19 May 2006

Revised 17 July 2006

Accepted 21 July 2006

\begin{abstract}
Department of Biochemistry and Microbiology, School of Medicine, Loma Linda University, Loma Linda, CA 92350, USA
\end{abstract}

\begin{abstract}
The authors have shown previously that the vimA gene, which is part of the $b c p-r e c A$-vimA operon, plays an important role in protease activation in Porphyromonas gingivalis. The gingipain RgpB proenzyme is secreted in the vimA-defective mutant $P$. gingivalis FLL92. An important question that is raised is whether the $\operatorname{vim} A$ gene product could directly interact with the proteases for their activation or regulate a pathway responsible for protease activation. To further study the mechanism(s) of VimA-dependent protease activation, the vimA gene product was further characterized. A $39 \mathrm{kDa}$ protein consistent with the size of the predicted VimA protein was purified. In protein-protein interaction studies, the VimA protein was shown to interact with gingipains RgpA, $\mathrm{RgpB}$ and Kgp. Immune sera from mice immunized with $P$. gingivalis immunoreacted with the purified VimA protein. Taken together, these data suggest an interaction of VimA with the gingipains and further confirm the role of this protein in their regulation or maturation.
\end{abstract}

\section{INTRODUCTION}

The expression of extracellular proteolytic activities is highly regulated in both prokaryotic and eukaryotic systems. This regulation can occur at multiple levels, including expression of the protease genes, secretion, processing of an inactive secreted precursor to its active form and/or the posttranslational glycosylation of the proteins (Gallagher et al., 2003; Bosques et al., 2004). The multiple layers of regulation are vital to ensure that expression is tightly controlled in the appropriate temporal and spatial patterns.

Porphyromonas gingivalis, a black-pigmented Gram-negative anaerobic bacterium, is an important aetiological agent of chronic adult periodontitis and is associated with other systemic diseases (Amano, 2003; Amano et al., 2000; Deshpande et al., 1998; Grau et al., 2004). While several virulence factors have been implicated in the pathogenicity of $P$. gingivalis, the high proteolytic abilities of this organism have been the focus of much attention, and appear to play an important role in virulence. The major proteases, called gingipains, are both extracellular and cell-associated. They consist of arginine-specific protease [Arg-gingipain (Rgp)] and lysine-specific protease [Lys-gingipain (Kgp)] (Nakayama, 2003).

tPresent address: Department of Biological Sciences, Oakwood College, Huntsville, AL, USA.

‡Present address: School of Public Health, Tianjin Medical University, China.
The mechanism of gingipain regulation in $P$. gingivalis is unclear. We have shown that the vimA gene can modulate the phenotypic expression of the gingipains in $P$. gingivalis (Abaibou et al., 2001; Olango et al., 2003; Vanterpool et al., 2005b). The vimA gene is part of the bcp-recA-vimA transcriptional unit (Fig. 1). A vimA-defective mutant strain designated $P$. gingivalis FLL92 was non-black pigmented and showed significant reductions in proteolytic, haemolytic and haemagglutinating activities (Abaibou et al., 2001). While a reduction in Arg-X- and Lys-X-specific proteolytic activities was observed in $P$. gingivalis FLL92, transcription of the gingipain genes was unaltered in these mutants compared to that of the wild-type strain (Abaibou et al., 2001). A similar phenotype of the gingipain genes was also seen in $P$. gingivalis FLL32, a recA- and vimE-defective isogenic mutant that had reduced Arg-X-and Lys-X-specific proteolytic activities (Abaibou et al., 2000; Vanterpool et al., 2004). While there was a unique late onset of Arg-X- and Lys-X-specific proteolytic activity in $P$. gingivalis FLL92, there was little or no observed change of proteolytic activity in stationary-phase in P. gingivalis FLL93, a vimE-defective mutant (Vanterpool et al., 2004). Collectively, these observations have raised the question whether the regulation of proteolytic activity in $P$. gingivalis may occur by multiple mechanisms. Further, it is unclear if the vimA gene product can physically interact with the gingipains or regulate a pathway for protease maturation/activation. To investigate the mechanism of VimA-dependent gingipain biogenesis, the vimA gene product was further characterized. The results described here demonstrate an interaction 


\begin{tabular}{|c|c|c|c|c|}
\hline $\begin{array}{c}\text { Plays a role in } \\
\text { DNA damage and } \\
\text { may play a role in } \\
\text { regulating } \\
\text { virulence }\end{array}$ & $\begin{array}{c}\text { Play a role in regulating the maturation } \\
\text { and activation of the major virulence } \\
\text { factors }\end{array}$ & $\begin{array}{c}\text { Also play a role in carbohydrate } \\
\text { biogenesis }\end{array}$ & $\begin{array}{c}\text { glycosyltransferase } \\
\text { that plays a role in the } \\
\text { maturation and } \\
\text { activation of the major } \\
\text { virulence factors }\end{array}$ \\
\hline
\end{tabular}

Fig. 1. The recA-vimA-vimE-vimF virulenceregulating locus of $P$. gingivalis and roles of the genes in this bacterium. See Vanterpool et al. (2005) for the role of vimF. of VimA protein with the gingipains and further confirm a possible role of this protein in their regulation.

\section{METHODS}

Cloning of vimA into an expression vector. Oligonucleotide primers specific for the ORF of the vimA gene were synthesized ( vimA forward, 5'-ATGCCCATCCCTCTATACCTG-3'; $\operatorname{vimA}$ reverse, 5'-TACCTGTTTTTGCTGACCGG-3') and used in PCR amplification of the $\operatorname{vim} A$ gene as previously described (Abaibou et al., 2001). The fragment carrying the $\operatorname{vim} A$ gene was cloned into pCRT7/CT-TOPO expression plasmid (Invitrogen) carrying coding for a C-terminal His-tag. The recombinant plasmid, designated pFLL131, was transformed into competent BL21(DE3)pLysS Escherichia coli. The orientation was determined by restriction endonuclease digestion. The nucleotide sequence of the insert in pFLL131 was analysed by DNA sequencing to rule out any mutations.

Expression and purification of rVimA. E. coli BL21(DE3)pLysS carrying pFLL131 was grown to exponential phase $\left(\mathrm{OD}_{600} 0 \cdot 7\right)$ in Luria-Bertani broth in the presence of carbenicillin $\left(50 \mu \mathrm{g} \mathrm{ml}^{-1}\right)$ and chloramphenicol $\left(24 \mu \mathrm{g} \mathrm{ml}^{-1}\right)$. IPTG to a final concentration of $1 \mathrm{mM}$ was added at exponential phase and the culture was incubated at $37^{\circ} \mathrm{C}$ with shaking for a further $6 \mathrm{~h}$. Cells were harvested by centrifugation and lysed by sonication as previously reported (Johnson et al., 2004). Cell membranes and debris were then harvested by centrifugation, and the supernatant and pellet were analysed for the recombinant protein, rVimA, by SDS-PAGE. The insoluble rVimA was solubilized from the pellet with $6 \mathrm{M}$ guanidine $/ 20 \mathrm{mM}$ sodium phosphate $/ 0.5 \mathrm{mM} \mathrm{NaCl}$. For large-scale preparation, rVimA was purified by FPLC using a HiTrap Chelating Ni-NTA column (GE Healthcare). rVimA was eluted using guanidine elution buffer ( $6 \mathrm{M}$ guanidine, $20 \mathrm{mM}$ sodium phosphate, $0.5 \mathrm{mM} \mathrm{NaCl}, 0.5 \mathrm{M}$ imidazole). Eluate fractions were analysed for rVimA by SDS-PAGE. Desired fractions were then pooled and dialysed against $8 \mathrm{M}$ urea buffer $(8 \mathrm{M}$ urea, $20 \mathrm{mM}$ sodium phosphate, $0.5 \mathrm{mM} \mathrm{NaCl})$ followed by a protein-binding buffer $(20 \mathrm{mM}$ sodium phosphate, $0 \cdot 5 \mathrm{mM} \mathrm{NaCl}, 0 \cdot 5 . \mathrm{M} \mathrm{L}$-arginine). For small-scale preparation, a Ni-NTA magnetic bead and magnetic separator (Qiagen) was used to purify the recombinant protein according to the manufacturer's recommendations. The presence of the poly-histidine tag was confirmed using the GelCode $6 \times$ His Protein Tag kit according to the manufacturer's instructions (Pierce).

Preparation of extracellular fractions of $\boldsymbol{P}$. gingivalis. $P$. gingivalis W83 was grown to stationary phase $\left(\mathrm{OD}_{600} 1 \cdot 5\right)$ from actively growing cells. Cells were harvested by centrifugation at $10000 \mathrm{~g}$ for $30 \mathrm{~min}$. The cell-free culture fluid was precipitated with $37 \cdot 5 \%$ or $60 \%$ acetone $\left(-20{ }^{\circ} \mathrm{C}\right)$, and the protein pellet was resuspended in $7 \mathrm{ml} 100 \mathrm{mM}$ Tris/HCl buffer ( $\mathrm{pH} 7 \cdot 4)$ in the presence of $1 \mathrm{mM} \mathrm{N}$ p-tosyl-L-lysine chloromethyl ketone (TLCK), dialysed for $24 \mathrm{~h}$ against the same buffer and then stored on ice or at $0{ }^{\circ} \mathrm{C}$.

Protein-protein interaction studies. Approximately $75 \mu \mathrm{g}$ of the purified rVimA protein was incubated with the Ni-NTA-linked magnetic beads. The beads with attached $\mathrm{rVimA}$ were washed with wash/interaction buffer $\left(50 \mathrm{mM} \mathrm{NaH}{ }_{2} \mathrm{PO}_{4}, 300 \mathrm{mM} \mathrm{NaCl}, 50 \mathrm{mM}\right.$ imidazole and $0.005 \%$ Tween 20) and incubated with purified extracellular RgpB from P. gingivalis (Athens Research Technology) or with cell lysates or extracellular proteins from $P$. gingivalis W83 or FLL92. As a negative control, the lysates or extracellular fractions from $P$. gingivalis were incubated with the magnetic beads without the attached rVimA. After incubation, the unbound proteins were eliminated by repeated washing in wash/interaction buffer. Proteins were eluted off the beads under denaturing conditions $[1 \times$ lithium dodecyl sulfate (LDS) sample buffer incubated at $90^{\circ} \mathrm{C}$ for $\left.5 \mathrm{~min}\right]$.

Gel electrophoresis and immunoblot analysis. SDS-PAGE was performed with a $4-12 \%$ Bistris separating gel in MOPS-SDS running buffer(NuPAGE Novex gels; Invitrogen) according to the manufacturer's instructions. Samples were prepared (65\% sample, $25 \%$ $4 \times$ NuPAGE LDS sample buffer, $10 \%$ NuPAGE reducing agent), heated at $72{ }^{\circ} \mathrm{C}$ for $10 \mathrm{~min}$ and then electrophoresed at $200 \mathrm{~V}$ for $65 \mathrm{~min}$ in the XCell SureLock Mini-Cell System (Invitrogen). The protein bands were visualized by staining with Simply Blue Safe stain (Invitrogen). The separated proteins were then transferred to BioTrace nitrocellulose membranes (Pall Corporation) and processed at $15 \mathrm{~V}$ for $25 \mathrm{~min}$ with a Semi-Dry Trans-blot apparatus (Bio-Rad). The blots were probed with gingipain-specific antibodies (Potempa et al., 1998). The secondary antibody used was immunoglobulin $\mathrm{G}$ (heavy plus light chains)-horseradish peroxidase conjugate (Zymed Laboratories). Immunoreactive proteins were detected using the Western Lighting Chemiluminescence Reagent Plus kit (Perkin-Elmer Life Sciences).

Identification of proteins that can physically interact with rVimA. Proteins in the eluates from the Ni-NTA magnetic beads (with or without the attached rVimA) were separated by SDS-PAGE and stained. Bands were excised using a gel cutter and dried in a Speed Vac (Savant Instruments) for $1 \mathrm{~h}$. Dried gel bands were reduced with $20 \mu \mathrm{l} 20 \mathrm{mM}$ tri(2-carboxyethyl)phosphine(TCEP) at $56^{\circ} \mathrm{C}$ and then alkylated with $20 \mu \mathrm{l} 40 \mathrm{mM}$ iodacetamide for $30 \mathrm{~min}$ at $23{ }^{\circ} \mathrm{C}$. Alkylated samples were then washed twice with $100 \mathrm{mM}$ ammonium bicarbonate and dried using the Speed Vac for $1 \mathrm{~h}$. Fifteen microlitres of digestion buffer $\left(15 \mu \mathrm{l}\right.$ of $0.05 \mu \mathrm{g} \mu \mathrm{l}^{-1}$ trypsin stock diluted in $3 \%$ acetic acid) was added to the dried gel slices and incubated for $10 \mathrm{~min}$ on ice. Excess digestion buffer was removed and $10 \mu \mathrm{l} 100 \mathrm{mM}$ ammonium bicarbonate was added to cover the gel slices in order to prevent drying. The gel slices were then incubated for $16 \mathrm{~h}$ at $30^{\circ} \mathrm{C}$. After $16 \mathrm{~h}$, an additional $10 \mu \mathrm{l}$ $100 \mathrm{mM}$ ammonium bicarbonate was added to gel slices followed by incubation for an additional $30 \mathrm{~min}$ at $30^{\circ} \mathrm{C}$. Proteins were then trapped, washed and eluted using ZipTip C18 $_{18}$ according to the manufacturer's instructions (Millipore). Eluted peptides were dried in the Speed Vac for 5-10 min and resuspended in $0.05 \%$ trifluoroacetic acid (TFA) in MS-grade water. All buffers were prepared in $100 \mathrm{mM}$ ammonium bicarbonate. Tryptic peptides were separated and analysed on a Picoview model PV-500 Nanospray ESI unit (New Objective) coupled to an LCQ Deca XP ion trap mass spectrometer (Thermo Electron) using a four-event programme consisting of a 
full MS scan followed by three MS/MS events for the most intense ions on full MS. A $75 \mu \mathrm{m} \times 10 \mathrm{~cm}$ capillary column packed with $5 \mu \mathrm{m} \mathrm{C}-18$ coated silica was developed with a 40 min gradient elution programme of $2-90 \%$ acetonitrile buffered with $0.5 \%$ acetic acid and $0 \cdot 005 \%$ TFA at a flow rate of $300 \mathrm{nl} \mathrm{min}^{-1}$. Data were collected with the Xcalibur software (Thermo Electron) and screened using Bioworks 3.1 Turbosequest software (Thermo Electron) against a pgin.fasta database downloaded from the Los Alamos National Laboratory (http://www.oralgen.lanl.gov) website. Peptide tandem mass spectra were screened to filter out low/poor-quality spectra. Individual peptide matches were also confirmed manually using the BLAST database at http://www.oralgen.lanl.gov. Proteins were considered to be identified if at least two different peptides were identical matches.

Immunization of ApoE mice with $\boldsymbol{P}$. gingivalis. Mating pairs of C57BLK mice (male $\mathrm{ApoE}^{-1-}$ ) were purchased from Jackson Laboratories. Breeding of $\mathrm{ApoE}^{(+/-)}$mice was performed at the Animal Care Facility of Loma Linda University. Male and female mice were pair-housed (monogamous pairing: one male and one female). The litters were weaned between 21 and 28 days and separated into male and female groups ( 5 animals per group). The animals were challenged with $P$. gingivalis according to the method described by Baker et al. (2000). At 10 weeks, the animals were infected by oral gavage three times at 2 day intervals with $10^{9}$ c.f.u. of live $P$. gingivalis W83 or $P$. gingivalis FLL92 in $100 \mu \mathrm{l}$ PBS containing $2 \%$ carboxymethylcellulose. Controls included sham-infected mice, which received the carboxymethylcellulose gavage without $P$. gingivalis (W83/FLL92). At 14 or 24 weeks after the first gavage, mice were euthanized using $\mathrm{CO}_{2}$. The blood was collected by cardiac puncture. Sera collected were stored at $-80^{\circ} \mathrm{C}$. Similarly, the sera of unimmunized (baseline) animals were collected and stored at $-80{ }^{\circ} \mathrm{C}$. These experiments were performed under authorization of a Loma Linda University approved animal use protocol (OSR \#83045).

\section{RESULTS}

\section{Bioinformatic analysis of VimA}

BLAST and homology searches of VimA failed to yield matches to any known or conserved proteins or enzymic domains in the databases (http://www.oralgen.lanl.gov or http://www.ncbi.nlm.nih.gov). However, hydrophobicity scaling (http://www.tigr.org) of the VimA protein showed approximately 20 aa residues located at the $\mathrm{N}$-terminus to be hydrophobic. This could suggest that this protein is a putative membrane protein.

\section{rVimA interacts with the major gingipains of $\boldsymbol{P}$. gingvalis W83}

We have previously shown that inactivation of the vimA gene alters the maturation of the gingipains (Olango et al., 2003; Vanterpool et al., 2005b; Fig. 1). Expression of the cloned His-tagged vimA ORF in E. coli BL21(DE3)pLysS cells as described in Methods, followed by purification using a Ni-NTA column, showed that $\operatorname{vimA}$ encodes the expected $39 \mathrm{kDa}$ recombinant protein (data not shown). To determine if VimA can interact with the gingipains, rVimA attached to Ni-NTA magnetic beads was incubated with cell lysates from $P$. gingivalis W83 or FLL92. As a negative control, the lysates were incubated with the magnetic beads without the recombinant protein. As shown in Fig. 2(a), multiple proteins that interacted with rVimA were detected. Western blot analysis of the eluates using anti-RgpA and anti-Kgp antibodies showed immunoreactive bands consistent with the catalytic and haemagglutinin domains of RgpA and Kgp (Fig. 2b, c). In addition, an immunoreactive $50 \mathrm{kDa}$ band and bands ranging from 70 to $90 \mathrm{kDa}$ representing the catalytic $\mathrm{RgpB}$ and membrane-type RgpB, respectively, were observed (Fig. 2d). To determine if rVimA could interact with the mature processed gingipain, magnetic beads with $\mathrm{rVimA}$ attached were incubated with purified RgpB. As shown in Fig. 3, a $50 \mathrm{kDa}$ band, consistent with the size of RgpB, was observed only when VimA was incubated in the presence of the extracellular fraction from $P$. gingivalis.

\section{rVimA interacts with possible regulatory proteins}

To identify other proteins that may interact with $\mathrm{rVimA}$, protein bands from the eluates were analysed by LC-MS. In addition to two sugar metabolism proteins, $\beta$-lactamase and a putative sialidase, several hypothetical proteins and the HtrA homologue were also identified to interact with $\mathrm{rVimA}$ in vitro (Table 1). LC-MS analysis of interacting partners of rVimA interestingly demonstrated a unique 26 aa peptide residue (RACEMEGIHTFDFEGSMLEGIEGFFR) present on the hypothetical protein PG1833 and also the periplasmic serine protease HtrA. This 26 aa residue is not part of the predicted sequence of these proteins (http://www.oralgen. lanl.gov) but is identical to the amino acid sequence near the C-terminus of the VimA protein (see http://www.oralgen. lanl.gov for the full sequence).

\section{VimA is antigenic in an ApoE mouse model}

To determine if the VimA protein is exposed to the host's immune system, sera from mice challenged with the parent strain or the vimA-defective isogenic mutant were examined. Western blot analysis using sera from animals immunized with $P$. gingivalis W83 exhibited immunoreactivity with rVimA (Fig. 4). In contrast, sera from animals not immunized with $P$. gingivalis, or immunized with the vimA-defective mutant FLL92, exhibited no immunoreactivity with the rVimA protein. Taken together, these results suggest that the vimA gene product is immunogenic in the ApoE mice.

\section{DISCUSSION}

VimA is a putative membrane protein that appears to play a role in virulence regulation in $P$. gingivalis via gingipain biogenesis (Abaibou et al., 2001; Olango et al., 2003; Vanterpool et al., 2005b). If $v i m A$ is part of a pathway(s) that is involved in the maturation and/or activation of the gingipains, then it is likely that VimA could interact with the gingipain. Our studies have indicated that rVimA may indeed interact with the gingipains from $P$. gingivalis. The fact that $\mathrm{rVimA}$ interacted with RgpB only in the presence of 


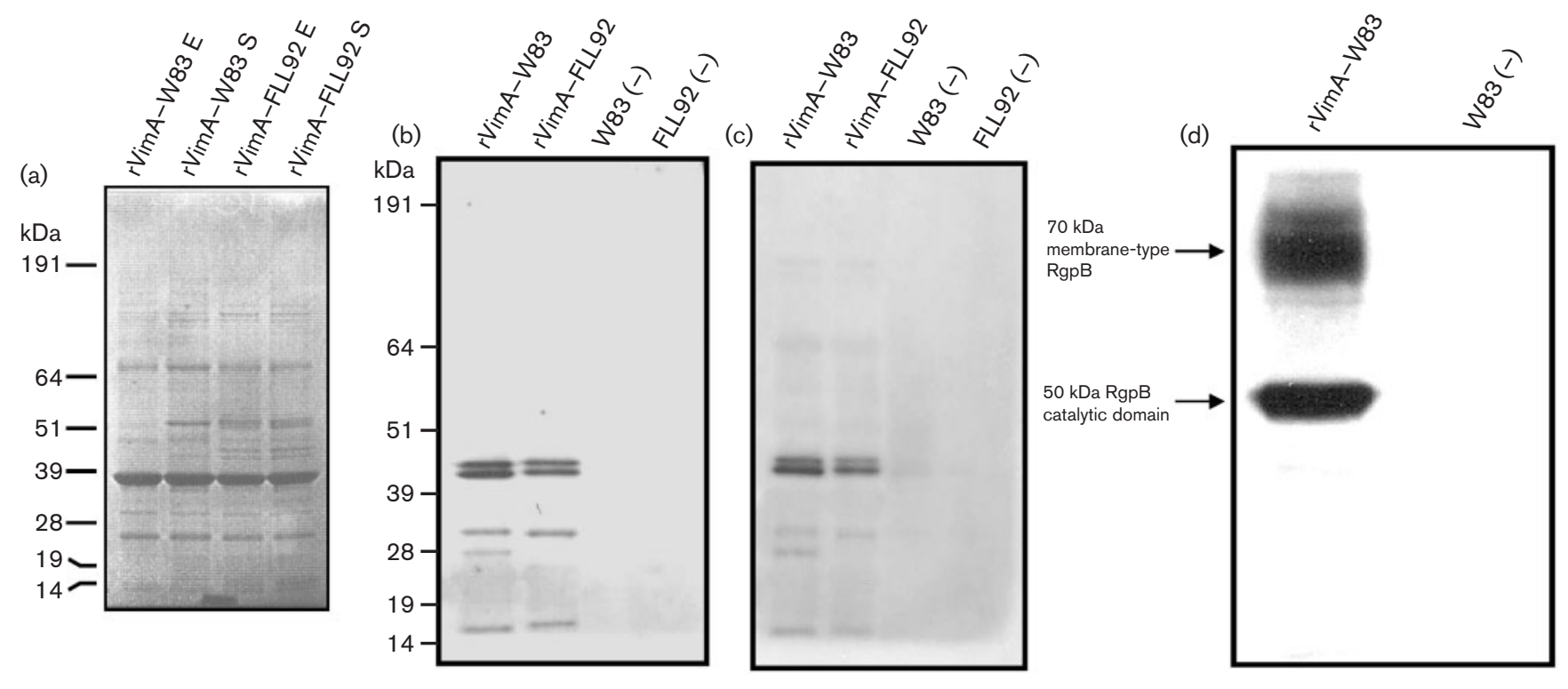

Fig. 2. $r$ VimA interacts with gingipains $\operatorname{RgpA}, \operatorname{RgpB}$ and $\mathrm{Kgp}$. (a) Eluates from interaction studies with cell lysates of $P$. gingivalis W83 and FLL92 in the exponential phase (E) or stationary phase (S) were separated by SDS-PAGE and stained with SimplyBlue Safestain. $(b-c)$ Eluates from protein interactions with lysates prepared from cells grown to late exponential phase were analysed by immunoblotting using gingipain-specific antibodies: anti-RgpA (b), anti-Kgp (c) or anti-RgpB (d). W83 (-), P. gingivalis W83 incubated with beads only; FLL92 (-), P. gingivalis FLL92 incubated with beads only (negative controls).

other extracellular proteins may suggest that this interaction occurs via a protein complex. The presence of the $70 \mathrm{kDa}$ $\mathrm{RgpB}$ in the interaction studies using cell lysates and its absence using RgpB from extracellular fractions indicates that, in addition to the $50 \mathrm{kDa}$ matured form of RgpB, rVimA can also interact with the heavily glycosylated membrane-type RgpB, which is not found in the extracellular fractions.

Several other proteins were observed to interact with rVimA. These proteins in other systems are known to be involved in post-translational regulation. The multifunctional periplasmic HtrA protein is a heat-shock-induced serine protease which is important in many organisms. At low temperatures it can provide chaperone function. However, proteolytic activity is induced at high temperature. HtrA has also been shown to degrade misfolded proteins; it can play a role in oxidative stress resistance and can regulate growth at high temperature (az-Torres \& Russell, 2001; Cortes et al., 2002; Foucaud-Scheunemann \& Poquet, 2003; Lipinska et al., 1990; Lyon \& Caparon, 2004; Pallen \& Wren, 1997; Poquet et al., 2000). In addition, HtrA is involved in the maturation of proteins, including cysteine protease (Poquet et al., 2000; Foucaud-Scheunemann \& Poquet, 2003; Lyon \& Caparon, 2004). The inactivation of HtrA has also resulted in attenuated virulence in several organisms (Cortes et al., 2002; Lyon \& Caparon, 2004). The regulatory role(s) of HtrA in P. gingivalis is unclear. Our preliminary studies have shown that HtrA can interact with and regulate the gingipains under environmental stress conditions (data not shown). Thus, the interaction of VimA with HtrA further confirms a regulatory role of VimA in P. gingivalis; however, its specific mechanism is unclear and is currently under investigation.

Glycosylation is a post-translational regulatory mechanism that is important in gingipain biogenesis in $P$. gingivalis (Gallagher et al., 2003; Curtis et al., 1999; Vanterpool et al., 2005a, b). Further, the post-translational addition of carbohydrates to the gingipains is highly variable, thus implicating a role for multiple factors in this process. In this study, the VimA protein was also observed to interact with the $\beta$-lactamase and sialidase proteins, which are known to play a role in sugar metabolism (Ishikura et al., 2003; Smayevsky et al., 2001; Brook, 1989; Hedberg \& Nord, 1996; Sechi et al., 2004). Although sialylation can be involved in protein maturation, its role, if any, in gingipain biogenesis is unknown. Furthermore, we cannot rule out the possibility that the VimA protein may regulate the function of these proteins via a common mechanism shared with the gingipains. Carbohydrates biogenesis was altered in a $P$. gingivalis vimA-defective mutant (Vanterpool et al., 2005b). The presence of sialidase in many organisms suggests that sialidase activity may be important for colonization and/or pathogenicity. In $P$. gingivalis, similar to many organisms, the sialidase may cleave selected sugar moieties from tissues, leaving them susceptible to cleavage by proteolytic enzymes, such as the gingipains. The physical interaction of the sialidase with VimA could further suggest a role for VimA in the coordinate regulation of several of the virulence factors 


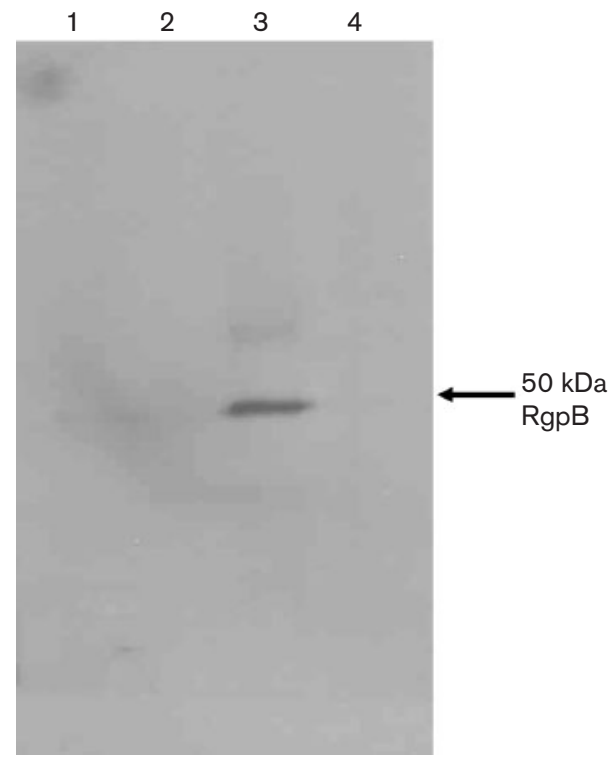

Fig. 3. Interaction of VimA with matured processed RgpB. Purified RgpB and extracellular proteins of $P$. gingivalis W83 were incubated with Ni-NTA beads in the presence or absence of $r$ imA. Eluates of the protein interaction were separated by SDS-PAGE and subjected to immunoblot analysis with RgpBspecific antibodies as probes. Lanes: 1, purified $\operatorname{RgpB}$ in the presence of $\operatorname{VimA} ; 2$, purified $\mathrm{RgpB}$ in the absence of $\operatorname{VimA}$; 3 , $P$. gingivalis W83 extracellular proteins in the presence of VimA; 4, P. gingivalis W83 extracellular proteins in the absence of VimA.

of this organism. The role of this sialidase gene in $P$. gingivalis is being further evaluated in our laboratory.

Many cellular processes are facilitated by supramolecular complexes (Sheng \& Sala, 2001). Several protein domains have been described in both eukaryotic and prokaryotic systems that are involved in protein-protein interactions in these complexes (Pawson et al., 2002; Ponting, 1997; Sheng \& Sala, 2001; Agrawal \& Kishan, 2002).

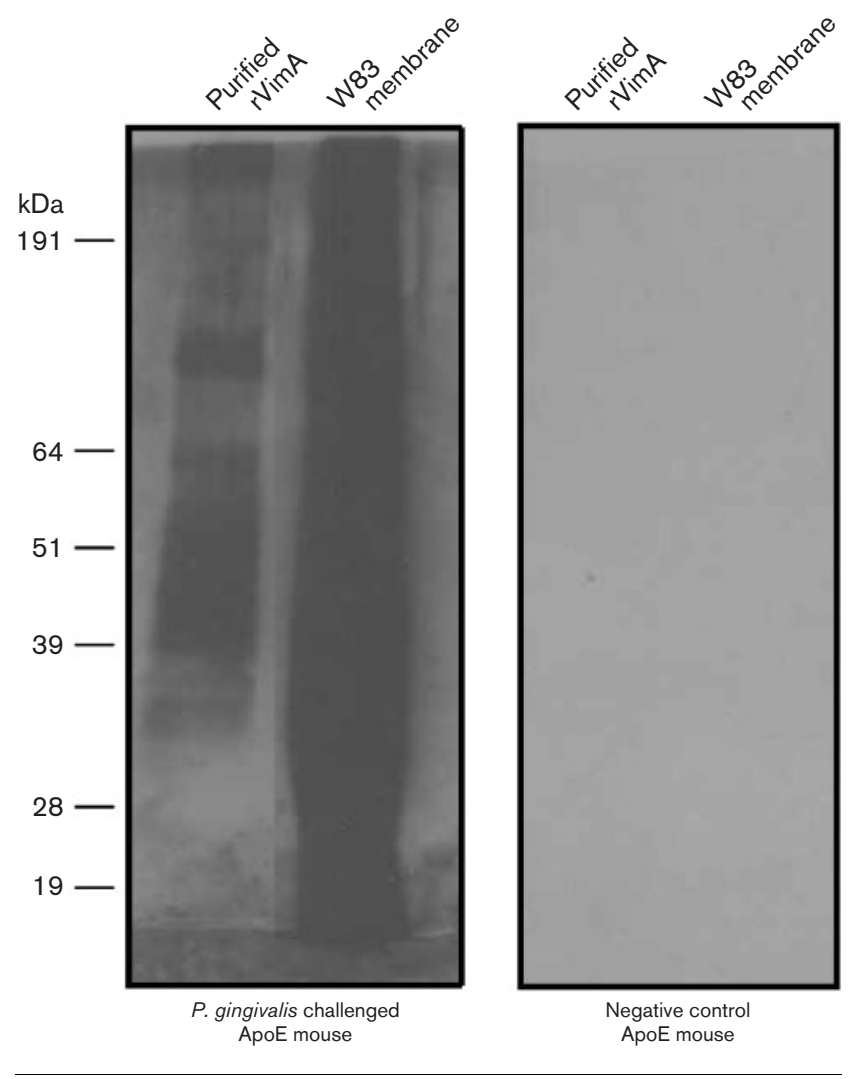

Fig. 4. VimA is antigenic in a mouse model. Serum was drawn from $P$. gingivalis-challenged ApoE mice after immunization. Sera from challenged mice were then used as primary antibodies against purified $r$ VimA protein during immunoblotting.

We demonstrated the presence of a 26 aa residue of VimA on two P. gingivalis proteins, $\mathrm{HtrA}$ and hypothetical protein PG1833, which would be consistent with the hypothesis that these proteins can interact. This 26 aa sequence may be a direct interaction site, but we cannot rule out the possibility that its presence on HtrA and PG1833 is due to heavy contamination from the rVimA bait. The HtrA protein has PDZ domains that are known to interact with

Table 1. Proteins that interact with recombinant VimA

\begin{tabular}{|lll|}
\hline Gene ID & \multicolumn{1}{c|}{ Protein } & \multicolumn{1}{c|}{ Description } \\
\hline PG1101 & Alanyl-tRNA synthase & Translation \\
PG0535 & HtrA & Serine periplasmic protein \\
PG1833 & Conserved hypothetical protein & Unknown \\
PG1337 & Hypothetical protein & Unknown \\
PG0324 & Conserved hypothetical protein (putative sialidase) & Unknown \\
PG1768 & RgpA & Arg-gingipain \\
PG0461 & RgpB & Arg-gingipain \\
PG1605 & Kgp & Lys-gingipain \\
PG0010 & $\beta$-Lactamase & Energy/sugar metabolism \\
\hline
\end{tabular}


the C-terminus of other proteins. Similar to the HtrA protein in other organisms, this protein in $P$. gingivalis shares a similar structure (http://www.oralgen.lanl.gov; http://www.tigr.org) (Ponting, 1997). A preliminary structural analysis (data not shown) of the protein encoded by the PG1833 gene shows a transmembrane protein with a domain that is conserved among several other proteins of unknown function (http://www.oralgen.lanl.gov; http:// www.tigr.org). The function of this domain and its importance in the interaction of VimA are currently being investigated in our laboratory. Collectively, however, these data may suggest that a complex of proteins could be involved in gingipain biogenesis in $P$. gingivalis. It is unclear whether VimA may have an 'adaptor' protein function similar to what occurs during caspase activation (Boatright et al., 2003; Boatright \& Salvesen, 2003a, b). The gingipain RgpB has been shown to have a caspase-like fold (Eichinger et al., 1999).

Finally, the ability of sera from animals immunized with $P$. gingivalis to recognize VimA indicates that this protein is exposed to the immune system during the course of an infection. This would be consistent with a putative membrane location for VimA and could have therapeutic implications.

In summary, our data have demonstrated an interaction of VimA protein with the gingipains and other proteins that could affect its maturation/activation. This further supports a possible role of this protein in their regulation. The specific mechanism of VimA-dependent regulation in $P$. gingivalis is being further investigated in our laboratory.

\section{ACKNOWLEDGEMENTS}

This work was supported by Loma Linda University School of Dentistry and by Public Health Service grants DE13664 and DE13664S1 from the National Institute of Dental and Craniofacial Research (to H.M.F) and GM60507, a minority training grant from the National Institute of General Medicine. We would also like to thank Dr Jan Potempa for the gingipain antibodies.

\section{REFERENCES}

Abaibou, H., Ma, Q., Olango, G. J., Potempa, J., Travis, J. \& Fletcher, H. M. (2000). Unaltered expression of the major protease genes in a non-virulent recA-defective mutant of Porphyromonas gingivalis W83. Oral Microbiol Immunol 15, 40-47.

Abaibou, H., Chen, Z., Olango, G. J., Liu, Y., Edwards, J. \& Fletcher, H. M. (2001). vimA gene downstream of recA is involved in virulence modulation in Porphyromonas gingivalis W83. Infect Immun 69, 325-335.

Agrawal, V. \& Kishan, K. V. (2002). Promiscuous binding nature of SH3 domains to their target proteins. Protein Pept Lett 9, 185-193.

Amano, A. (2003). Molecular interaction of Porphyromonas gingivalis with host cells: implication for the microbial pathogenesis of periodontal disease. J Periodontol 74, 90-96.

Amano, A., Kuboniwa, M., Nakagawa, I., Akiyama, S., Morisaki, I. \& Hamada, S. (2000). Prevalence of specific genotypes of
Porphyromonas gingivalis fimA and periodontal health status. J Dent Res 79, 1664-1668.

az-Torres, M. L. \& Russell, R. R. (2001). HtrA protease and processing of extracellular proteins of Streptococcus mutans. FEMS Microbiol Lett 204, 23-28.

Baker, P. J., DuFour, L., Dixon, M. \& Roopenian, D. C. (2000). Adhesion molecule deficiencies increase Porphyromonas gingivalisinduced alveolar bone loss in mice. Infect Immun 68, 3103-3107.

Boatright, K. M. \& Salvesen, G. S. (2003a). Caspase activation. Biochem Soc Symp 233-242.

Boatright, K. M. \& Salvesen, G. S. (2003b). Mechanisms of caspase activation. Curr Opin Cell Biol 15, 725-731.

Boatright, K. M., Renatus, M., Scott, F. L. \& 8 other authors (2003). A unified model for apical caspase activation. Mol Cell 11, 529-541.

Bosques, C. J., Tschampel, S. M., Woods, R. J. \& Imperiali, B. (2004). Effects of glycosylation on peptide conformation: a synergistic experimental and computational study. J Am Chem Soc 126, 8421-8425.

Brook, I. (1989). Pathogenicity of the Bacteroides fragilis group. Ann Clin Lab Sci 19, 360-376.

Cortes, G., de Astorza, B., Benedi, V. J. \& Alberti, S. (2002). Role of the htrA gene in Klebsiella pneumoniae virulence. Infect Immun $\mathbf{7 0}$, 4772-4776.

Curtis, M. A., Thickett, A., Slaney, J. M., Rangarajan, M., AduseOpoku, J., Shepherd, P., Paramonov, N. \& Hounsell, E. F. (1999). Variable carbohydrate modifications to the catalytic chains of the RgpA and RgpB proteases of Porphyromonas gingivalis W50. Infect Immun 67, 3816-3823.

Deshpande, R. G., Khan, M. B. \& Genco, C. A. (1998). Invasion of aortic and heart endothelial cells by Porphyromonas gingivalis. Infect Immun 66, 5337-5343.

Eichinger, A., Beisel, H. G., Jacob, U., Huber, R., Medrano, F. J., Banbula, A., Potempa, J., Travis, J. \& Bode, W. (1999). Crystal structure of gingipain R: an Arg-specific bacterial cysteine proteinase with a caspase-like fold. EMBO J 18, 5453-5462.

Foucaud-Scheunemann, C. \& Poquet, I. (2003). HtrA is a key factor in the response to specific stress conditions in Lactococcus lactis. FEMS Microbiol Lett 224, 53-59.

Gallagher, A., Aduse-Opoku, J., Rangarajan, M., Slaney, J. M. \& Curtis, M. A. (2003). Glycosylation of the Arg-gingipains of Porphyromonas gingivalis and comparison with glycoconjugate structure and synthesis in other bacteria. Curr Protein Pept Sci 4, 427-441.

Grau, A. J., Becher, H., Ziegler, C. M. \& 7 other authors (2004). Periodontal disease as a risk factor for ischemic stroke. Stroke 35, 496-501.

Hedberg, M. \& Nord, C. E. (1996). Beta-lactam resistance in anaerobic bacteria: a review. J Chemother 8, 3-16.

Ishikura, H., Arakawa, S., Nakajima, T., Tsuchida, N. \& Ishikawa, I. (2003). Cloning of the Tannerella forsythensis (Bacteroides forsythus) siaHI gene and purification of the sialidase enzyme. J Med Microbiol 52, 1101-1107.

Johnson, N. A., Liu, Y. \& Fletcher, H. M. (2004). Alkyl hydroperoxide peroxidase subunit $\mathrm{C}(a h p C)$ protects against organic peroxides but does not affect the virulence of Porphyromonas gingivalis W83. Oral Microbiol Immunol 19, 233-239.

Lipinska, B., Zylicz, M. \& Georgopoulos, C. (1990). The HtrA (DegP) protein, essential for Escherichia coli survival at high temperatures, is an endopeptidase. J Bacteriol 172, 1791-1797.

Lyon, W. R. \& Caparon, M. G. (2004). Role for serine protease HtrA (DegP) of Streptococcus pyogenes in the biogenesis of virulence factors SpeB and the hemolysin streptolysin S. Infect Immun 72, 1618-1625. 
Nakayama, K. (2003). Molecular genetics of Porphyromonas gingivalis: gingipains and other virulence factors. Curr Protein Pept Sci 4, 389-395.

Olango, G. J., Roy, F., Sheets, S. M., Young, M. K. \& Fletcher, H. M. (2003). Gingipain RgpB is excreted as a proenzyme in the vimAdefective mutant Porphyromonas gingivalis FLL92. Infect Immun 71, 3740-3747.

Pallen, M. J. \& Wren, B. W. (1997). The HtrA family of serine proteases. Mol Microbiol 26, 209-221.

Pawson, T., Raina, M. \& Nash, P. (2002). Interaction domains: from simple binding events to complex cellular behavior. FEBS Lett 513, 2-10.

Ponting, C. P. (1997). Evidence for PDZ domains in bacteria, yeast, and plants. Protein Sci 6, 464-468.

Poquet, I., Saint, V., Seznec, E., Simoes, N., Bolotin, A. \& Gruss, A. (2000). HtrA is the unique surface housekeeping protease in Lactococcus lactis and is required for natural protein processing. Mol Microbiol 35, 1042-1051.

Potempa, J., Mikolajczyk-Pawlinska, J., Brassell, D., Nelson, D., Thogersen, I. B., Enghild, J. J. \& Travis, J. (1998). Comparative properties of two cysteine proteinases (gingipains R), the products of two related but individual genes of Porphyromonas gingivalis. J Biol Chem 273, 21648-21657.
Sechi, L. A., Karadenizli, A., Deriu, A., Zanetti, S., Kolayli, F., Balikci, E. \& Vahaboglu, H. (2004). PER-1 type beta-lactamase production in Acinetobacter baumannii is related to cell adhesion. Med Sci Monit 10, BR180-BR184.

Sheng, M. \& Sala, C. (2001). PDZ domains and the organization of supramolecular complexes. Annu Rev Neurosci 24, 1-29.

Smayevsky, J., Canigia, L. F., Lanza, A. \& Bianchini, H. (2001). Vaginal microflora associated with bacterial vaginosis in nonpregnant women: reliability of sialidase detection. Infect Dis Obstet Gynecol 9, 17-22.

Vanterpool, E., Roy, F. \& Fletcher, H. M. (2004). The vimE gene downstream of vimA is independently expressed and is involved in modulating proteolytic activity in Porphyromonas gingivalis W83. Infect Immun 72, 5555-5564.

Vanterpool, E., Roy, F. \& Fletcher, H. M. (2005a). Inactivation of $\operatorname{vimF}$, a putative glycosyltransferase gene downstream of vimE, alters glycosylation and activation of the gingipains in Porphyromonas gingivalis W83. Infect Immun 73, 3971-3982.

Vanterpool, E., Roy, F., Sandberg, L. \& Fletcher, H. M. (2005b). Altered gingipain maturation in vimA- and vimE-defective isogenic mutants of Porphyromonas gingivalis. Infect Immun 73, 1357-1366. 